\title{
The Changing Powers of Readers in a Time of New Technology
}

\author{
Margaret Mackey, Ph.D. \\ <margaret.mackey@ualberta.ca> \\ Assistant Professor \\ School of Library and Information Studies, University of Alberta \\ Canada
}

Today's young people are used to moving in a world of multiple media and formats; they take the ability to move from one platform to another completely for granted. A qualitative study enlisted a small number of students in fifth and eighth grades (all with a background of domestic computer ownership and use) for intensive work with texts in different media. This report on part of that study demonstrates that those who have grown up with domestic access to video, computers, and the Internet are often relatively neutral when it comes to platform, preferring to judge texts by issues of personal salience and fluency of access.

\section{Introduction}

There are three things that have revolutionized academic life in the last twenty years, though very few people have woken up to the fact: jet travel, direct-dialling telephones and the Xerox machine. - Professor Morris Zapp (Lodge, 1984, p.43)

Morris Zapp, speaking in David Lodge's Small World: An Academic Romance, describes a revolution that many of us will remember. Lodge's novel, after all, was published as recently as 1984 and set in 1979 - hardly remote history. Yet Morris Zapp's revolution seems in retrospect to be both short-lived and remarkably cumbersome. Seen from the vantage point of a mere fifteen years later, it is startling to see Lodge's academics, presumably on the front line of communicating information, yet still dealing with the material movement of ideas. In our own era of cut-and-paste, downloaded documents, and email attachments, their reliance on actual transport, real-time communication, and ever-increasing stacks of paper looks remarkably laborious.

1984, the year of Small World, also marked the birth of babies who are now fifteen years old. In the West, many of these young people have grown up in a world where information has lost its dependence on real time, real movement, and real paper. They may take a historical interest in Morris Zapp's version of revolution, but what they truly take for granted is instant access and a broad range of media and technologies. Adults, of course, also know about the technological developments but may find it more difficult to comprehend the impact of the taking for granted part of this description. This paper explores this issue. 
It is an exciting time to be interested in broad questions of literacy. Even a definition of what we mean today when we use the word "reading" is fluid; does it include issues of visual literacy, media literacy, computer literacy, consumer literacy? Even if we define reading strictly as the processing of print, there is no question that what young people learn about approaching print is affected by what they know about texts in other media. Children who have watched many hours of television have certain expectations about the shaping of a story; children who gain a great deal of their information online or from CD-ROM encyclopedias are influenced in how they learn to establish what is salient to their search by skimming and scanning.

Only by standing back a little can we gauge the scale of contemporary change. There was a time long ago when, for large numbers of people, print offered the only real and regular entrance point to somebody else's imagined world. Drama was live; it took place in the theatre or on the village green. It was also correspondingly rare, compared to the dozens of hours now available on television every single day.

Raymond Williams draws our attention to the impact of media changes on our perceptions of drama:

It is in our own century, in cinema, in radio and in television, that the audience for drama has gone through a qualitative change. I mean not only that Battleship Potemkin and Stagecoach have been seen by hundreds of millions of people, in many places and over a continuing period, nor only that a play by Ibsen or O'Neill is now seen simultaneously by ten to twenty million people on television. This, though the figures are enormous, is still an understandable extension. It means that for the first time a majority of the population has regular and constant access to drama, beyond occasion or season. But what is really new - so new I think that it is difficult to see its significance - is that it is not just a matter of audiences for particular plays. It is that drama, in quite new ways, is built into the rhythms of everyday life. On television alone it is normal for viewers - the substantial majority of the population - to see anything up to three hours of drama, of course drama of several different kinds, a day. And not just one day; almost every day. This is part of what I mean by a dramatized society. In earlier periods drama was important at a festival, in a season, or as a conscious journey to a theatre; from honouring Dionysis or Christ to taking in a show. What we now have is drama as habitual experience: more in a week, in many cases, than most human beings would previously have seen in a lifetime. (1983, p.12)

In this past era, other forms of mediated text were very rare or nonexistent. So print carried the imaginations of millions into far-flung realms - and also carried the can for the mind-rot that set in as a consequence! We may be a bit inclined to look back on a golden age of print, but it seems clear that people in the past saw as many problems with too much print fiction as they do nowadays with violent video games. Catherine Sheldrick Ross, writing about series books, quotes the chief librarian of the Boy Scouts of America who, in 1914, complained as follows about dime novels: 
The fact is that the harm done [by these cheap books] is incalculable. I wish I could label each one of these books: "Explosive! Guaranteed to Blow Your Boy's Brains Out."... [A]s some boys read such books, their imaginations are literally "blown out," and they go into life as terribly crippled as though by some material explosion they had lost a hand or foot. (quoted in Ross, 1995, p.203)

The tone of the complaint is surprisingly familiar but we are not used to hearing such strictures applied to print works; this kind of vocabulary is now reserved for movies and video games.

Nowadays, of course, young people in the West at least can enter imaginary worlds through a variety of portals: print, television, video, computer game, movie, audio text, interactive website (multi-user dungeons and so forth). It is now an unusual child who sticks completely to one medium alone. Our understanding of how literacy works for today's young people will be broader and more useful if we take account of how they accommodate and make sense of texts in different formats.

Access to media and technology is expanding rapidly, especially in North America, though it is a long way from universal. According to Nua's ongoing survey of online numbers worldwide, as of June 1999102.03 million people, both adults and children, in Canada and the United States have accessed the Internet at least once during the three months prior to being surveyed. The world figure for the same date was 179 million. (<http:/www.nua.ie/surveys/how_many_online /index.html>, June 25, 1999) Another survey, based on questionnaires mailed to 50,000 homes in the United States, found that, by the end of 1998, 50.3\% of American homes had at least one computer. (Half of U.S. households, C5) Nua's estimates for the future are also startling: they suggest that 13.7 under-eighteen-year-olds in North America are expected to be online by 2001, a number that will "surge" to 36.9 million by 2005 . Not surprisingly, the North American total stands out as a disproportionate fraction of the estimated 77 million youths worldwise who are expected to be online by the year 2005. (<http://www.nua.ie/surveys/index. cgi?f=VS\&art_id=905354860\&rel=true $>$, June 29, 1999)

In North America, ownership of television sets is very close to $100 \%$ and all indications are that ownership of at least one VCR is moving towards $90 \%$ of households. Radio is similarly ubiquitous. CD-players, tape recorders, and Walkmans are commonplace.

\section{Research Questions}

Thus it really makes sense to talk about reading in expanded terms that take account of broadbased access to many different media. Very few people indeed come to print texts without a vast background of exposure to texts in many other media. Understanding the consequences of this phenomenon raises a number of interesting questions.

- What are the consequences of multimedia exposure and experience for readers' tacit understandings of how texts work?

- What repertoires of strategies and behaviours help people to process story and information in different media? 
- How does experience in different media and platforms affect people's strategic approaches to texts in different formats?

- What individual quirks or patterns of response, if any, manifest themselves across media boundaries?

A longitudinal study of a small number of young people who were in fifth, eighth, and eleventh grades when the work began was the basis for an exploration of these questions. A total of nineteen students participated in all or part of the project, which lasted for about twenty months. This report describes part of the first section of that study, namely the responses of some of these participants in fifth and eighth grades to the openings of fifteen texts in three different media. Their reactions give some glimpses of a new textual world.

\section{Methodology}

The researcher worked with a small number of school students in fifth, eighth and eleventh grades, monitoring their responses to texts in print, video and CD-ROM form in order to explore such questions. These students are bright and privileged. They have access to computers at home and have done so since they were young children, they are used to playing multimedia games, they take home video equipment utterly for granted - and, it is important to stress, they still like to read books. The eighth-graders were all born in 1984, the year David Lodge published Small World with its account of an information revolution that was already being superseded. To all of these young people, the revolution described by Morris Zapp would indeed seem like ancient history; some of them, most likely, have never used a dial telephone.

The choice to work with young people who have access to a wide variety of media was deliberate in the interest of exploring what happens to young readers who grow up in a setting where they can take the proliferation of home technology as a given. The issue of differential access to technology is a vast and important question but not explored here. Hoping to gain some sense of what the future may look like, the researcher selected participants who are at home in a multimedia world already.

One participant at a time, thirteen students looked at the first page of five different novels, the opening credits of five movies on video, and the early stages of five narrative-based CD-ROMs. Students were to say if they would continue further with each text and why, and what they thought might happen in each story based on what they had seen so far. Their responses were audio-recorded and transcribed.

I held some titles in common across grade levels, and also offered some titles in more than one medium. The complete list follows: 


\begin{tabular}{|c|c|c|}
\hline $5^{\text {th }}$ grade: & $\underline{\text { Videos }}$ & $\underline{\mathrm{CD}-\mathrm{ROMs}}$ \\
\hline Anne of Green Gables & Anne of Green Gables & Anne of Green Gables \\
\hline The Secret Garden & The Secret Garden & Oregon Trail \\
\hline My Teacher is an Alien & Toy Story & My Teacher is an Alien \\
\hline The Watsons Go to Birmingham & Air Bud & The Jolly Post Office \\
\hline The Golden Compass & Little Women (animation) & Alien Tales \\
\hline $8^{\text {th }}$ grade: & $\underline{\text { Videos }}$ & $\underline{\mathrm{CD}-\mathrm{ROMs}}$ \\
\hline Anne of Green Gables & Anne of Green Gables & Anne of Green Gables \\
\hline My Teacher is an Alien & Toy Story & My Teacher is an Alien \\
\hline The Watsons Go to Birmingham & Casablanca & Virtual Springfield \\
\hline Cat's Eye & Men in Black & Men in Black \\
\hline The Golden Compass & Benny and Joon & Discworld II \\
\hline $11^{\text {th }}$ grade: & $\underline{\text { Videos }}$ & $\underline{\mathrm{CD}-\mathrm{ROMs}}$ \\
\hline Cat's Eye & Casablanca & Tex Murphy \\
\hline Soul Music & Benny and Joon & Starship Titanic \\
\hline Middlemarch & Middlemarch & Discworld \\
\hline Sophie's World & Toy Story & Sophie's World \\
\hline The Golden Compass & Men in Black & Men in Black \\
\hline
\end{tabular}

\section{Findings}

There is not room in a short paper to outline detailed responses to each of these texts. A few general observations, supported with details from the transcripts, make the point.

Overall, these readers were relatively indifferent to platform. They showed no signs of having an automatic preference for one medium over another; instead, they judged each text on its merits. No one rejected all the texts in a single medium or selected all the texts in a single medium without qualification. 
In many cases, the students applied a yardstick to the text in question that can best be described as a balance between questions of salience and questions of fluency, or ease of access. They queried whether the text was saying something that they wanted to hear, for whatever reason. They also queried whether they could gain access to that text without undue aggravation or difficulty. These questions arose in all media and were sometimes answered differently for the same title when it appeared in more than one format.

\section{Example 1: The Fifth-Graders}

Questions of salience as weighed against fluency came up in many different forms. Here, for example, is Colin, a fifth-grader, on the book version of My Teacher is an Alien. He would not read further than page one in this book:

I don't really like books about boys and they pick on little people and then there's little people trying to find ways, like, to get away from the bullies or whatever. . . It's about, kind of like, like school kids that kind of, umn, like, he likes to read and, like, he's getting picked on by the bully guy.

Colin's aversion to reading about bullies was his primary response to the book. He was much more attracted to the CD-ROM version of the story, which, not surprisingly, places a much stronger emphasis on the game-playing side of things. Colin played the game for as long as I allowed him, and said he would play much more given the opportunity. It was the different salience that he commented on, rather than the shift of medium. He would expect that "you would keep on going to different classrooms and find different things and then find the classroom with the Principal guy in it."

Colin also took fluency into account with some of his decision-making. He rejected the blackand-white video of the old movie version of The Secret Garden: "I don't really like movies in black and white because it's kind of hard to decipher one thing from another."

Megan, also a fifth-grader, looked at the book of Anne of Green Gables and also made a decision based on ease of access: "I don't think I would read that one. They use big words and it's sort of confusing." Asked what sort of story she would expect it to be, Megan said, "Umh, like one where she ventures a lot and stuff. I've read one like it." The combination of big words and perceived lukewarm plot is clearly unappealing.

Yet Megan did not reject dense text outright. Given the first page of The Golden Compass, she said she would read it because "it describes a lot, like the things. I like that because you can, like, picture it." And Megan did not reject the "ventures and stuff" of Anne Shirley when presented with the story in video form, where the emotional impact of the unwanted orphan is more instantly established. She would watch more, she said, because "I would want to see, like, what happened to Anne."

Megan's responses show an active balancing between how difficult and how interesting she found the stories. The fourth word of The Golden Compass is "daemon," a more challenging concept than any of the words or ideas in the opening page of Anne of Green Gables. Yet the leisurely discourse of the Montgomery book does not offer her any reason to persevere with the story, even though, as she demonstrated over and over again during this project, she is a reader 
who actively enjoys description. The direct narrative compulsion of the opening page of The Golden Compass clearly caught her attention in a more dynamic way that outweighed any obstacles that unfamiliar words might present.

Megan and Colin present an interesting contrast when shown the early stages of the video of a Japanese animation of Little Women. Megan rejected the idea of watching any further; she had read an abridged version of the novel and not cared for it; furthermore, "I don't really like the way, like, they're drawn and stuff. They're sort of different. I don't like it that way." She also rejected the plot line: "Like umh, the father is gone and everything like that. Umh, and that's like, what they talk about a lot and so it's mostly, like, there's stuff happening but they also just talk about that lots."

Colin, on the other hand, was reminded of a Japanese animation he described as his favourite movie. He would watch more of Little Women, he said, because "I like the animation and it's kind of gotten an interesting start."

Angela, a third fifth-grader, was explicit about issues of adaptation. She preferred the movie of Anne of Green Gables to the book by a slim margin, having experienced both:

Well, it's kind of hard to say. You had to sit quite long through the movie. It was pretty long but it, you could, it almost expressed the, umh, what was happening better 'cause you could actually see. Like when she dyed her hair green and whatever. That was, I think, better. I like imagining it well enough but the movie was pretty good.

Yet Angela normally prefers the book version:

I don't usually always like the movies. Sometimes they change things a whole bunch. So they're not - well, to some people they might be better, but to me, I like them the way they kind of were in the book. Like, sometimes they, some movies that they've made, they just twisted the stories around and if I had read the story first I probably would have liked it because it was more realistic and original....

As a reader of Little Women, Angela rejected the Japanese animated version for two reasons: "it's not really like the book and it's...the characters look like Sailor Moon characters. Like, I would watch it but it wouldn't be a main priority." Asked whether she thought the animation did justice to the characters of the book, she said:

They're not exactly, well they have the same hobbies and everything, but they just don't seem the way they are in the book so - maybe not the same, well I noticed that Meg didn't have the same hair or whatever, or they didn't - usually they act all together and not separate. And well, I know that Jo likes to write stories and she's a bit of a free will, but I mean, in cartoons I don't think it looks as good.

These fifth-graders are explicitly drawing on intertextual references to help them establish issues of salience and accessibility. There are many versions of, "I read/saw/played one like this and it was satisfying/frustrating," both in terms of content and in terms of processing. Similarly, questions of provenance and recommendation arise often. In conversation students often make reference to how they had encountered a book and what impact this had on their selections. A friend's seal of approval, a formal award, some recognition that someone else had enjoyed this story, might predispose these participants to look more favourably on an opening scene. 
Nasrin, an eighth-grader, was explicit about questions of salience and fluency in her discussion of Anne of Green Gables.

On first looking at a photocopy of page one of Anne of Green Gables, Nasrin said, "This seems a little too advanced, umh, of what I would normally read, but if it was recommended by a friend or had won an award, then I'd probably read it." Questions of fluency would impinge on her interest in the book, on the strength of the first page only, but might be over-ridden by some form of recommendation. As she picked up the book and looked at it, however, we can see issues of salience take over. After a single glance at the back of the book she said,

Now I'd probably read it! The back simplifies it, from the first text, from the page on the first text so I - actually I like books like this because I, I'd also pick it because I'm not an orphan and I'd probably want to know how it feels to be an orphan, so just for the experience of it, "cause a lot of books, they can do that.

The leisurely and loquacious introduction to Anne of Green Gables antagonized many of these young readers, but not all, and one exception was a reminder that gender stereotypes are not necessarily the whole story when it comes to describing readers. Jack was an eighth-grader who would keep reading Anne of Green Gables:

I would definitely keep going because it sounds like a book that would tell a good story. It would tell a descriptive story that made a lot of sense. I like the way it's written. . . . I mean, I found some old books that I wouldn't read recently, and it was all like, "Bob said..." and it was written not, they were good stories, but it wasn't written well enough to keep me interested - so I like this book a lot.

One of the interesting elements of the students' responses is that issues of salience and fluency apply to all the media we explored. Here, for example, is Anita, an eighth-grader, asked if she would watch more of the movie Casablanca:

Probably not because even from the start I didn't even understand it so, umh, it seems more like a history movie to me. Although I don't really think that's what it's supposed to be, but I think I probably just wouldn't pay attention, I'd just lose track. It would be a waste of my time.

Fluency and salience are both affected by repertoire in this instance. Anita makes a genre link to a history movie of the kind that would be offered in a social studies class, and this is not an unreasonable connection given the introductory map and the newsreel-style voiceover at the outset of Casablanca. At the same time, she recognizes that she does not have an immediately accessible repertoire of background information that would render this movie quickly transparent to her, so she rules it out.

The computer game of Men in Black provided some interesting examples of differing responses. The question of fluent access arose very sharply for many users. Unlike all the other games on offer, it runs on keyboard controls rather than on the mouse. The opening scenes are rigidly organized and if you do not choose correctly you are blown up very quickly. On the other hand, most of the eighth-graders who looked at this game were familiar with the movie and indeed had 
just seen the opening credits as part of the video collection, so some questions of salience were straightforward.

Anita rejected the CD-ROM because of the violence, though she had enjoyed the movie. She also disliked the keyboard control. Catherine also rejected it, but more for the absence of action combined with the cumbersome quality of the keyboard controls: "It's pretty complicated and you just get to walk around and that." Madeleine was another player who rejected the game; she likes action games but only if they are easy to play and this one was too complicated for her - a textbook case of balancing salience and fluency.

In this case, Jack proved that gender stereotypes sometimes do ring true. He knew the movie well and had actually played a demo version of the computer game of Men in Black. The issue of fluency played itself out differently for him: "I like the keyboard because you, it's - because I think you have more control. You know where you're going, you can't skip." Possessing a set of skills more appropriate to the requirements of the game, he was able to comment, "I like it. I think it's easy to navigate and, umh, it makes sense. There's a story that begins to develop and ah, yeah, it's more fun!" Again, it is possible to see him weighing the trade-off between interest and accessibility.

\section{Conclusions}

The above sampling of comments gives only a taster of a fascinating collection of responses. These young people are clearly accustomed to making judgments about whether a text is worth the investment of their time and were able to articulate their reasoning in a very informative way. It is very clear from the transcripts that these students are used to having a broad range of texts to choose from; they did not express any great commitment to persevering with a story that struck them as dull, although one or two did mention that they might expect a text to get better after the first confusing stages.

Weighing the balance between personal salience and fluency of access was a strategy that manifested itself across all three media and for many different texts. The students explicitly worked on a kind of trade-off: the more salient the story, the more prepared they were to invest time and effort into reading or viewing or playing. It is worth noting that there were some examples in which fluency and salience were a two-way measure; students rejected some texts because they seemed too simple either in terms of writing or in terms of content.

Students were clear that some stories work better in one format than in another, but at all times it appeared to be the story they were judging; the platform was an issue only as it provided appropriate access to the story in question. All students testified to enjoying stories in each of the three media we were discussing-print, video, and CD-ROM.

Asked a general question about which of the fifteen texts they would most like to take home, the students came had varied answers. Six said they would take a book. Three opted for video and two for a CD-ROM. Three added a qualifier that they would not really like to choose between one and another, that they have different preferences at different times of day and so forth. Whatever the effects of easy access to different media upon these students, it is clear that the book continues to be a meaningful choice for them. 
If a single sentence could sum up this part of the project, it would be that these young people demonstrate a predilection not for "either/or" when it comes to media but rather for "both/and." They are interested in and also selective about all forms of media. They are able to discriminate in meaningful ways among texts and to articulate the reasons for their choices. They are neither overly dazzled by bells and whistles, nor dismissive of print. They confound many stereotypes about their generation and perhaps about the nature of the communications revolution. We may learn much of value about the future of stories in many media through listening to their youngest consumers.

\section{References}

Computer economics: 77 million under 18s online globally by 2005 . $<$ http://www.nua.ie/surveys/index.cgi?f=VS\&art_id=905354860\&rel=true $>($ June 29, 1999).

Half of U.S. households have PCs, survey says. (March 30, 1999). Globe and Mail, C5.

Lodge, David. (1984). Small world: An academic romance. London: Penguin Books, 1985.

Nua Internet How Many Online. <http://www.nua.ie/surveys/how_many_online/index.html.> (June 25, 1999).

Ross, Catherine Sheldrick. (1995) "If they read Nancy Drew, so what?": Series book readers talk back. Library and Information Science Research 17, 201-236.

Williams, R. (1983). Writing in society. London: Verso. 